\title{
Psychological Denial
}

National Cancer Institute

\section{Source}

National Cancer Institute. Psychological Denial. NCI Thesaurus. Code C99675.

A psychological defense mechanism that allows a person to avoid the reality of the situation by refusing to acknowledge it. 